\title{
Scientific Careers and the Mobility of European Researchers: An Analysis of International Mobility by Career Stage
}

Submitted to Higher Education (https://www.springer.com/journal/10734)

Carolina Cañibano

INGENIO (CSIC-UPV), Universitat Politècnica de València. Ciudad Politécnica de la Innovación, Edif 8E, 4a . Camino de Vera s/n, 46022 Valencia, Spain

ORCID ID: 0000-0002-7683-930X

Corresponding author: ccanibano@ingenio.upv.es

Pablo D'Este

INGENIO (CSIC-UPV), Universitat Politècnica de València. Ciudad Politécnica de la Innovación, Edif 8E, $4^{\mathrm{a}}$. Camino de Vera s/n, 46022 Valencia, Spain.

ORCID ID 0000-0002-4040-8209

F. Javier Otamendi

Universidad Rey Juan Carlos, Facultad de Ciencias Jurídicas y Sociales, Paseo de Artilleros s/n, Vicálvaro, 28032 Madrid, Spain

ORCID ID: $\underline{0000-0001-6064-2724}$

Richard Woolley

INGENIO (CSIC-UPV), Universitat Politècnica de València. Ciudad Politécnica de la Innovación, Edif 8E, 4a . Camino de Vera s/n, 46022 Valencia, Spain

ORCID ID: $\underline{0000-0003-1247-8776}$ 


\title{
Scientific Careers and the Mobility of European Researchers: An Analysis of International Mobility by Career Stage
}

\begin{abstract}
International scientific mobility and research careers are two concepts that are intimately related. Yet, it has been very difficult for scholarship to pinpoint exactly how international mobility impacts on research careers. This paper contributes to this question by investigating links between international mobility, research career stage progression and job changes. It does so using a large-scale survey (MORE) which targets researchers based in European universities. The results establish that the profile of international mobility varies by academic research career stage. They also show that for researchers in the established mid-career phase who are working internationally, there are career advancements benefits associated with return mobility to their home country. However, these benefits may reduce if the timing of return is too delayed. The paper concludes by discussing the implications of these results for researcher mobility policy in the context of the European Higher Education Area and the European Research Area.
\end{abstract}

Key Words: research careers, scientific mobility, return mobility

\section{Acknowledgements}

The authors would like to thank the European Commission for facilitating access to the survey data, IDEA Consult for high quality project documentation and helpful advice on the conduct of the MORE series of studies, and Eric Iversen (NIFU) for expert clarification on data issues. This research was partly supported by funding received from the Research Infrastructure for Research and Innovation Policy Studies project (RISIS, contract number 313082). 


\section{Scientific Careers and the International Mobility of European Researchers}

\section{Introduction}

Academia has become increasingly globalised. Paradeise and Thoenig (2015) situate the latest turning point in the historical globalisation process of higher education at the beginning of the $21^{\text {st }}$ Century. According to Wächter (2008), following the $1980 \mathrm{~s}$ internationalisation moved from being a marginal element in higher education debates to a central indispensable one. The globalisation of academia goes in hand with an acceleration of flows and exchange of knowledge and people across national borders (Reale et al. 2019); with an increasingly internationalised academic job market (Paradeise and Thoenig 2015), and with the emergence of global norms and values in academic practices (Zippel 2017, 3). In the European context, the promotion of geographical mobility (of students, staff, teachers and researchers) became one of the core action lines of the Bologna Process for the construction of a European Higher Education Area (EHEA) (Bologna Declaration 1999).

Key among these globalised values are internationalisation and geographical mobility, which have become increasingly associated with academic quality and excellence (Ackers 2008). Ackers $(2008,2013)$ argues that following these globalising trends, mobility has become a 'rite of passage' in academic careers. The effects of mobility in terms of intercultural and linguistic development for mobile individuals have been shown in evaluations, particularly at the intra-European level (Wächter 2010). A number of studies address specifically the role of mobility in the early phases of research careers (Cañibano et al. 2008; Laudel 2005; Laudel and Bielick 2019). However, the patterns and functions of mobility at more consolidated and advanced stages of research careers remain under-explored.

This paper is located in the quantitative literature on international mobility and academic careers, focusing on a large-scale survey of researchers based in European universities (IDEA Consult 2013). It re-uses a dataset produced by the European Commission funded project MORE2 (IDEA Consult 2013). Re-use entails a range of methodological considerations relevant to open science and data-sharing, which constitute one contribution of this paper (section 5). 
The paper uses the MORE2 dataset to make novel contributions to the literature on international researcher mobility and academic careers. First, it compiles mobility profiles that describe differences in international mobility by career stage. Second, it finds that the effects of prior mobility experience and return mobility on research career advancement also vary by career stage. These results are relevant for both academic career studies and for policy design in the European Union, where academic/researcher mobility is viewed as an essential ingredient in the construction of both the EHEA and the European Research Area (ERA) (section 4.1, below).

\section{Linking research careers and international mobility}

Scientific mobility can be defined as mobility for the purpose of conducting research or research-related activities. As Mahroum (2000) describes, such movements often take place through the institutional channels which connect research groups, disciplinary communities and research performing organisations. Although scientific mobility is also sometimes used to refer to movements between scientific fields, topics, or organisation sectors, for example, in this paper our interest in scientific mobility is in international geographic mobility and its relationship with academic research careers.

International scientific mobility has been linked to academic careers in three main ways. First, international mobility allows researchers to participate in professional activities and opportunities that are important for their career development. Early career researchers can gain access to key postdoctoral labour market entry points (Melin, 2004; Marceau \& Preston, 1997). They can also integrate themselves with elite research networks, as Laudel (2005) demonstrated in the case of biomedical science. International mobility for $\mathrm{PhD}$ training or post-doctoral positions can build enduring and productive collaboration networks (Woolley et al. 2008), facilitate participation in prestigious international research projects (Barjack and Robinson 2008), and allow inexperienced researchers to access conditions suitable for developing their own independent research project (Laudel and Bielick 2019). International mobility can also provide access to promotions, income increases, improved working conditions, and allow for gains in prestige (Stephan 2015). Such activities accumulate both scientific credibility and social capital networks, which is why early career researchers tend to consider international mobility to be a vital personal strategy for career advancement 
(Musselin 2004), a way to increase their market value (Bauder 2015), and as having a generally positive impact on their careers (Børing et al. 2015).

Second, in an era of comprehensive research metrics that are often linked to individual evaluation for promotions or salary increments, international mobility has been linked to increases in researcher productivity. Quantitative studies of the effects of researchers' geographical mobility have found that there is a publication productivity return to international mobility (Franzoni et al. 2015, Lu and Zhang 2015, Gibson and McKenzie 2014, Moed et al. 2013, Asknes et al. 2013). Veugelers and van Bouwel (2015) find a productivity premium among mobile researchers to the United States compared to those who are mobile within the EU. However, other studies do not find an association between international mobility and publication productivity (Halevi et al. 2016, Cañibano et al. 2008). ${ }^{1}$

Third, although evidence is scarce and results are quite mixed, international mobility has been tentatively linked to accelerated career advancement in certain circumstances. Lawson and Shibayama (2015) address the effect of temporary international research visits on the dynamics of career promotion of a sample of Japanese academics in the biosciences. They investigate this relationship while taking into account these academics' previous mobility experiences, such as post-doctoral positions held abroad. They find that temporary stays abroad while holding a stable (tenured) position in Japan are positively associated with a reduced time to promotion upon return. However, they also find that international post-doctoral appointments have no lasting effect on career advance, which leads them to conclude that "mobility itself does not necessarily lead to career benefits for the researcher" (Lawson and Shibayama 2015, 14). Marinelli and colleagues (2014) also find mixed results regarding international mobility and career consolidation. For a sample of researchers from ten European countries, they find that non-mobile and returnee researchers are both more likely to achieve a tenured position when compared to migrants.

Of course, the relationship between international mobility and research careers is complicated by other variables. In particular there is considerable evidence that the

\footnotetext{
${ }^{1}$ As argued by Franzoni and colleagues (2015), with regard to self-reported survey response data there are reasons to believe that emigrants are positively selected among national populations of researchers. Gibson and McKenzie (2014) also point out that differences in the publication productivity of researchers' collectives with different geographical trajectories may result from selection effects, whereby it is the quality and productivity of a researcher that facilitates their international mobility rather than the reverse.
} 
international mobility of women researchers is different to those of male colleagues, due to child-rearing and other caring responsibilities (Ackers 2008, Reale et al. 2019). Whilst it seems apparent that certain scientific disciplines have higher rates of international mobility than others (IDEA Consult 2010, 2013), there is mixed evidence about whether disciplines have distinctive international mobility patterns (Halevi et al. 2016, IDEA Consult 2010, 2013). There is also some evidence that broader sociological factors such as social origins, experience of travel, and the number of languages spoken, can influence the propensity of individual researchers to undertake international research visits (Netz and Jaksztat 2017).

\section{Conceptual framework: international mobility and career stage}

This paper draws on concepts from the 'three careers' model of academic research careers developed by Grit Laudel and Jochen Gläser (Gläser and Laudel 2015; Laudel and Bielick 2019). They detail three intertwined career processes:

1. the cognitive career, "thematically connected problem solving processes in which findings from earlier projects serve as input in later projects";

2. the community career, a "series of status positions in the scientific community that are defined by the reputation a researcher has accrued and corresponding role expectations"; and

3. the organisational career, "a sequence of organisational positions which, through organisational role expectations, are linked to expectations concerning the conduct and content of research and opportunities to conduct research (access to salary, infrastructure, and other resources)" (Laudel and Bielick 2019: 3-4).

The community career passes through a series of stages (apprentice, colleague, master, elite) characterised by increased scientific autonomy, leadership and responsibility. Laudel and colleagues (Laudel et al. 2018) argue that research career progress tends to conform to disciplinary specific "scripts", or patterns of progress through these career stages, in which a researcher's scientific achievements and degree of peer recognition will be relatively more or less synchronised with the availability of appropriate organisational positions.

In empirical work utilising this career framework, Laudel and Bielick (2019) examine how disciplinary research practices shape mobility patterns in the transition from 
apprentice to colleague for early career researchers (ECRs). The importance of this paper is in demonstrating how mobility decisions are intertwined in functions for both the cognitive and organisational careers (Laudel and Bielick 2019, Table 5). Indeed, mobility can be understood as at times resolving tensions between the cognitive and organisational careers, for example where an ECR is ready to develop an independent research project but there is no position available to extend their tenure in their current organisation. Although this study only deals with the early career stage, it seems likely that the research practices of particular fields would also configure international mobility at later career stages.

As Laudel (2005) points out, being mobile at the ECR stage is also vital for connecting with the established elite within a scientific community. In this sense the 'brain drain' is an early career phenomenon, which refers to a country "losing potential members of the elite in their postdoctoral phase rather than losing its elite" (Laudel and Bielick 2019: 2). A key research question is then the existence of 'return mobility' and whether researchers who are mobile in early stages of the career are likely to return in later stages. From a 'three careers' perspective, this will be dependent on factors associated with the cognitive and peer community careers along with the availability of organisational positions of an appropriate rank.

Other research shows that mobility at the ECR stage is vital in accessing jobs and achieving career stability within an international environment of increased uncertainty and precariousness in academic labour markets (Fernández-Zubieta et al. 2015). Cañibano and colleagues (2008) found that Spanish ECR physicists and space scientists were more mobile at the postdoctoral stage than at the pre-doctoral stage, whereas molecular biologists and philosophers were more mobile in the pre-doctoral phase. Mobility has also been found to decline at later career stages (Bauder 2015) and to play a different role among established academics (Ackers and Gill 2008).

Although the available evidence is based on a small number of studies of selected fields, often based on scientists in one national science system, the impression is that international mobility is differently configured depending on researchers' career stage. It is this question which we will explore in our descriptive analysis. In our statistical analysis we focus on prior mobility experience and return mobility to examine whether these features have a distinct influence at different stages of the research career. The 
research questions are specified in section 5 (below), while the following section describes the research background and the study data.

\section{Research background, main definitions and data}

4.1 The European Higher Education Area (EHEA), the European Research Area (ERA) and researcher mobility

The European Higher Education Area (EHEA) emerged from the Bologna declaration of 1999 with the purpose of promoting higher compatibility and comparability of the systems of higher education in Europe. The ultimate goal of the EHEA is to "promote citizen's mobility and employability and the Continent's overall development" (Bologna Declaration 1999). The promotion, recognition and valorisation of mobility of students, teachers, researchers and university administrative staff are among the key objectives of the Bologna process.

In turn, steps towards the formation of the European Research Area (ERA) were first taken in 2000 (European Commission 2000) and consolidated through the Lisbon Treaty (2007). The ERA promotes the broad goals of improving national science and technology bases, enhancing regional and national competitiveness, and advancing coordination of member states in addressing societal grand challenges. The ERA was conceived with 'more abundant and more mobile human resources' as a foundational aspect (European Commission 2000). Priority 3 of the ERA is an 'open labour market for researchers' in which highly skilled and qualified persons can move seamlessly across borders to where their talents can be best employed (European Commission 2000). European and national policy support for this priority should seek to remove or alleviate barriers to mobility, ensure open merit-based recruitment, and facilitate job matching (EURAXESS portal).

In such a policy context, an important information support for both EHEA and ERA policymakers is the 'Support for Continued Data Collection and Analysis Concerning Mobility Patterns and Career Paths of Researchers' (MORE) projects funded by the EC. The keystone of these projects is a questionnaire delivered to a representative sample of researchers working in universities (IDEA Consult 2010, 2013, 2017). Results from the initial MORE survey highlighted that student mobility is a predictor of international 
mobility at later career stages (Børing et al. 2015) and that mobility to the USA is more beneficial to career progress than international mobility within Europe (Veugelers and Van Bouwel 2015).

\subsection{Main definitions and data}

Data used in this paper are from the second survey of European university researchers' mobility (MORE2). Among the main definitions used in MORE2, those relevant for our study are 'researcher', 'career stage' and 'mobility'. The definition of a researcher is derived from the Frascati Manual (OECD 2015). The MORE2 survey targeted individuals working in higher education institutions in Europe ${ }^{2}$ and "carrying out research, or supervising research, or improving or developing new products/processes/services, or supervising the improvement or development of new products/processes/services" (IDEA Consult et al. 2013: 56).

The definition of research career stages used derives from the European Commission Research Career Framework (European Commission, 2011). This framework defines four career stages in terms of the set of necessary and desirable research competences for each one of the stages. The focus on competences has the advantage of being applicable across different employment sectors, scientific fields and national institutional frameworks. The career stages specified are: R1 First Stage Researcher (up to the point of $\mathrm{PhD}$ ); $\mathrm{R} 2$ Recognised Researcher ( $\mathrm{PhD}$ holders or equivalent who are not yet fully independent); R3 Established Researcher (researchers who have developed a level of independence) and R4 Leading Researcher (researchers leading their research area or field).

The survey addressed a variety of types of scientific mobility but predominantly 'international mobility', on which our analysis is focused. A first set of questions on mobility captured information regarding several different reference countries, including the researcher's country of (first) citizenship, country of $\mathrm{PhD}$ award, country of residence and country of current employment. In addition, researchers holding a doctorate (that is at R2, R3 or R4 career stages) were asked to provide details regarding episodes of temporary mobility, which the survey refers to as "mobility instances". The

\footnotetext{
${ }^{2}$ Individual researchers currently working in the EU includes researchers working in the EU27 plus three associated countries (Iceland Norway, Switzerland) and three candidate countries in 2012 (Croatia, Macedonia (FYROM), Turkey) (IDEA Consult et al. 2013: 55). It includes researchers working in the EU, with and without EU citizenship or residence. It includes researchers who have been mobile outside the EU but have returned to work in the EU (IDEA Consult et al. 2013: 45).
} 
temporary mobility episodes reported had to be of a duration of more than three months and needed to have been undertaken in the previous ten years (up to a maximum of eight episodes). Whilst it makes sense to refer to the international mobility we study in this paper as 'mobility episodes', as we only work with those for which we have a start and end date, in the MORE2 project reports and documents the term 'mobility instances' is used. We use the two terms interchangeably from here on. Researchers were asked to provide a number of details regarding each mobility instance, including the year of the move, duration, destination country, career stage at the beginning and ending of each move, and information on whether the mobility involved changing employer. Regarding the most recent instance of mobility in their career, researchers were asked a set of additional questions about their motivations to move and barriers they may have encountered. The data on temporary geographical mobility compiled in this survey is thus very rich, providing an opportunity to compare mobility patterns across career stages for a large sample of researchers residing in Europe.

The final number of completed and eligible questionnaires was 10,547. The study target group is researchers at stages $\mathrm{R} 2+\mathrm{R} 3+\mathrm{R} 4$ of their career $(\mathrm{n}=8,357)$. Of this group $24 \%$ $(\mathrm{n}=1,999)$ reported at least one post-PhD instance of mobility of more than 3 months. A total of 3,217 post-PhD mobility instances of more than three months duration were reported. Out of the total number of mobility instances 64 were excluded from the analysis since their end date was missing. The final number of mobility instances included in the analyses that follow is 3,153 , performed by 1,995 researchers. . In the analyses that follow some variables refer to researchers undertaking mobility: gender, scientific field of work of the researcher, and country of $\mathrm{PhD}$. Most of the information characterises mobility instances, including mobility duration and career stage at start and end of the mobility episodes (among others). The return mobility and prior mobility variables combine information about researchers with mobility episodes.

Table 1 combines descriptive data regarding individuals and instances to provide an overview of mobility frequency for mobile researchers at each career stage. On average, the reported number of mobility instances per researcher is higher at the R4 stage than the R2 and R3 stages (Table 1), but the inverse is the case for women respondents. 
Table 1: International mobility instances by career stage, gender and field of science

\begin{tabular}{|c|c|c|c|c|c|c|}
\hline & \multicolumn{6}{|c|}{ Career Stage } \\
\hline & \multicolumn{2}{|c|}{$\mathbf{R 2}$} & \multicolumn{2}{|c|}{$\mathbf{R 3}$} & \multicolumn{2}{|c|}{ R4 } \\
\hline Gender & $\begin{array}{l}\text { Mobile } \\
\text { researchers }\end{array}$ & $\begin{array}{c}\text { Instances per } \\
\text { mobile } \\
\text { researcher }\end{array}$ & $\begin{array}{c}\text { Mobile } \\
\text { researchers }\end{array}$ & $\begin{array}{c}\text { Instances per } \\
\text { mobile } \\
\text { researcher }\end{array}$ & $\begin{array}{l}\text { Mobile } \\
\text { researchers }\end{array}$ & $\begin{array}{c}\text { Instances per } \\
\text { mobile } \\
\text { researcher }\end{array}$ \\
\hline Female $(n=657)$ & 452 & 1.43 & 199 & 1.41 & 58 & 1.31 \\
\hline Male $(n=1,338)$ & 798 & 1.39 & 459 & 1.33 & 273 & 1.57 \\
\hline \multicolumn{7}{|l|}{ Field of science } \\
\hline Agricultural Sciences & 30 & 1.57 & 24 & 1.46 & 18 & 2.06 \\
\hline Engineering and Technology & 199 & 1.41 & 94 & 1.32 & 53 & 1.53 \\
\hline Humanities & 138 & 1.58 & 96 & 1.58 & 45 & 1.64 \\
\hline Medical Sciences & 227 & 1.26 & 123 & 1.29 & 53 & 1.32 \\
\hline Natural Sciences & 360 & 1.44 & 141 & 1.37 & 75 & 1.56 \\
\hline Social Sciences & 296 & 1.38 & 180 & 1.27 & 87 & 1.45 \\
\hline Total & 1250 & 1.40 & 658 & 1.36 & 331 & 1.53 \\
\hline
\end{tabular}

The total number of mobile researchers is 1,995 . Some mobile researchers reported being mobile at multiple career stages, so the numbers of mobile researchers under the Career Stage columns do not sum to 1,995 . A total of $62.7 \%$ of the mobile researchers $(n=1,250)$ reported being mobile at $\mathrm{R} 2$ stage, $33.0 \%$ $(n=658)$ reported being mobile at R3 stage, and 16.6\% $(n=331)$ reported being mobile at R4 stage. Again, due to some mobile researchers reporting being mobile at multiple career stages these totals do not sum to $100 \%$. The average number of reported mobility instances per mobile researcher across all career stages was 1.58 .

\section{Data re-use, research questions and methods}

As was introduced above, the dataset for this study was produced by the MORE2 project to support the development of the EHEA and ERA (Idea Consult 2013). The authors of this paper were not associated with the questionnaire design or data collection that led to the dataset produced by MORE2. ${ }^{3}$ This paper is therefore a case of data re-use in the social sciences, which raises challenges for framing research questions and understanding whether the available data is likely to be a good fit for answering these questions (Doolan and Froelicher 2009; Hyman 1972). The authors had access to a range of publicly available reports on the survey results, the full text of the questionnaire and description of the variables, along with guidance on the sampling frame, country weightings and advice on using the data (Idea Consult 2013). In addition, the MORE 2 dataset is made available for research purposes through the Research Infrastructure for Science and Innovation Policy Studies (RISIS) project,

\footnotetext{
${ }^{3}$ Previous papers using the first MORE survey dataset were published by the co-designers of the questionnaire instrument (Børing et al. 2015) or included a substantial technical annex detailing the treatment of the sub-sample used, but without discussion of the issues involved in data re-use (Veugelers and Van Bouwel 2015).
} 
providing access to an anonymised and annotated version of the final project dataset. ${ }^{4}$ The authors were therefore able to access ample evidence that the data was of sufficiently high quality for their research purposes (Stewart and Kamins 1993). The authors then transferred the dataset to their data processing software and compared some self-generated descriptive statistics with the official project report in order to be satisfied that the transfer had occurred without any errors.

Along with the evident strengths of the dataset, we also had to consider its weaknesses in framing our research questions. The major weakness for our purposes was that information on changes in researchers' career stage (V5 in Table 2) was only available for researchers who had been internationally mobile for periods of three months or more. Combined with the fact that some questions in the survey were asked slightly differently of researchers who had been internationally mobile and those who had not, this meant that no comparisons could be made between mobile and non-mobile populations in this study. ${ }^{5}$ Instead the research questions framed for this paper only utilise data on the mobile sub-sample of researchers. This constitutes the major caveat on our eventual results, as we are unable to make any claims about the impact of mobility on the research community as a whole, but must restrict ourselves to those members of the community who have been internationally mobile.

We ascertained that detailed information on researchers' self-assessment of their current career stage had been gathered for the start and finish of every episode of mobility captured. ${ }^{6}$ This fitted well with the conceptual model of academic research careers guiding our approach (section 3), as it allowed for an interpretation of research careers that went beyond simply considering job changes to include perceptions of career progress in terms of the acquisition of professional competences (section 4.2). The information provided for current career stage and career stage advance can be considered to fall somewhere between the concepts of cognitive career and community career (Gläser and Laudel 2015) and to fold research achievements and professional recognition into the same scale, losing important detail as compared to the 'three careers' approach. However, as a proxy that allows us to investigate research careers as involving multiple processes and not revert to simply using organisational positions as a

\footnotetext{
${ }^{4}$ www.risis $2 . e u$

${ }^{5}$ See Veugelers and Van Bouwel (2015) for discussion of this weakness in the prior MORE study.

${ }^{6}$ Mobility instances for which either the start or end date were missing were eliminated from our analyses.
} 
unitary stand-in for career advancement, as most studies do, then these data appeared very useful - not least because to our knowledge such information has not been generated previously in a quantitative study.

The availability of this information allows us to link career progress to mobility episodes. It also allowed us to distinguish between mobility in which a change of employer occurred (change in the organisational career) and where mobility occurred within the tenure of a single organisational career position (e.g. research visits). The study was thus able to analyse the impact of international mobility of different institutional types on research careers, in a way that had not been done previously. In summary, these MORE2 data could thus be considered a good fit for developing research questions that also extend from our conceptual approach and address gaps in the existing literature (Hyman 1972).

First, we use data on instances of international mobility to compile descriptive profiles of international mobility by career stage. We use this descriptive analysis to address the following question: Are international mobility patterns dependent on researchers' career stage? (Research Question 1). According to our understanding of the literature on this topic (section 3), our initial expectation is that the profiles of international mobility associated with different career stages will be distinctive.

To address Research Question 1 we used all 3,153 mobility instances to construct mobility profiles for career stages (R2, R3, R4). We use hypothesis tests to compare patterns of mobility at different career stages in terms of the duration of mobility instances and whether these are associated with job changes, and to compare these results by gender and disciplinary field. For p-tests, relative frequencies are calculated for each group (R2, R3 and R4) and all the pair-wise differences in proportions are standardized at the $0.01,0.05$ and 0.10 significance levels. Additionally, we use researchers' self-reported motivations for international mobility to test whether these vary by career stages.

Second, we use information regarding the researchers' career stage at the beginning and end of each mobility instance to analyse possible associations between career stage advancement and two features of international mobility: prior mobility experience and return mobility. We initially address the question: Is career advancement positively associated with international mobility for mobile researchers? (Research Question 2a). 
In line with our conceptual model and the literature on the effect of career stage on international mobility patterns, we ask a further question: Does the association between career advancement and international mobility depend on the researchers' career stage at the time of the mobility? (Research Question 2b). Again our expectation is that mobile researchers' career stage will have an effect on the relationship between career advancement and these two features of international mobility.

The evidence that ECRs may need to be internationally mobile to establish their independence or work with elite members of the scientific community and the ongoing concerns about the potential effects of 'brain drain' (Cañibano and Woolley 2015), means there is particular research and policy interest in whether researchers who are internationally mobile ever return to their 'home' country. The MORE2 dataset contains comprehensive information that enables the identification of various types of 'return' within our sub-sample of internationally mobile researchers. The internationalization of higher education has added complexity to considerations of what is the 'home' country of an individual. A researcher's country of birth, country/ies of principal/secondary citizenship/residence and country of PhD training may all be different. In this study we opt to use information on country of $\mathrm{PhD}$ award as the home location for our analyses of 'return mobility'. Return is thus calculated as return to the country that invested in the researcher's $\mathrm{PhD}$ training.

There is some evidence in the literature showing that return mobility may be encouraged by the possibility of career advancement. For example, Musselin (2004: 67) describes how French researchers consider international mobility to be a "stepping stone to a good future position in their native country". Thorn and Holm-Nielsen (2006) point out the 'natural gravity' towards home that expatriate researchers experience, which may also encourage the maintenance of collaboration networks with the home country during international stays abroad (Andújar et al. 2015, Fontes 2007). The persistence of contacts and collaborations, along with 'insider' knowledge regarding institutional frameworks and the functioning of labour markets in the home country, may also help facilitate the return of expatriate researchers, particularly those who are able to negotiate and manage the timing and placement of their return. Return mobility is also considered by the European Commission as a key mechanism for maintaining the balance of highly qualified human resources across the European Research Area (Cañibano et al. 2017). 
Third, we use information on career stage and the researchers' mobility destinations to pose the questions: Is return mobility positively associated with career advancement for internationally mobile researchers? Does this relationship depend on the researcher's career stage at the time of the mobility? (Research Questions 3a/b) To respond to Research Questions 2a/b, 3a/b we build logit regression models that address the factors influencing the likelihood of career advancement associated with a mobility instance. We build two separate models to assess career transition of type R2-R3/R4 (from recognised to either established or leading researcher) and of type R3-R4 (from established to leading researcher).

Table 2 summarises the variables used in our descriptive and statistical analyses. Variable 'career advancement' (V5) provides the data necessary for building the models' dependent variable as it tells us whether the career stage of the researcher changed during a particular mobility instance. Variables 1-4 and 6-11 are included in the models as independent or control variables. Variable 'PhD age' (V10) is used to capture the time elapsed since the $\mathrm{PhD}$ was awarded and the mobility instance, while return mobility (V9) measures return by considering whether the destination country of the mobility instance coincides with $\mathrm{PhD}$ awarding country of the researcher. Descriptive statistics for variables used in the two logit models are included at Appendix A. 
Table 2: Variables used

Respondent variables

V1 Gender

Male; Female

V2 Field of research in current employment

Agricultural sciences

Engineering \& technology

Humanities

Medical sciences

Natural sciences

Social sciences

V3 PhD abroad: binary

Yes $=\mathrm{PhD}$ country differs from first citizenship country

V4 PhD country

Country where $\mathrm{PhD}$ was awarded

International mobility instance variables

V5 Career advancement: change in career stage at the start and the end of each mobility instance

Career advancement 1: from R2 to $\mathrm{R} 3$ or R4; Career advancement 2: from R3 to R4

V6 Duration of international mobility (months)

V7 Change of employer

Yes $=$ international mobility for new

$3-6 ; 6-12 ; 12-24 ; 24-36 ; 36+$

V8 Destination country

job

Destination country for international mobility

V9 Return mobility: binary

Yes $=$ destination country of international mobility is the same as PhD country (V4)

V10 PhD age:

Time elapsed between the award of the $\mathrm{PhD}$ and the start of the mobility instance (years)

V11 Prior mobility:

Number of a researcher's previous instances of international mobility, at the start of a mobility instance

V12 Factors determining the decision to See Table 5 move. (Only applies to the most recent instance of mobility reported.) 
There are limitations to these data that should be pointed out. Due to mobility information only being collected for the most recent ten years of the career, mobility at early career stages will most likely not be included for most senior researchers. Perception of timing of career stage transitions is self-reported and how this is understood is likely to vary.

\section{Results}

\subsection{Mobility profiles by career stage}

The first section of our empirical results characterizes mobility patterns at different career stages, using the mobility instance as the unit of analysis. We consider mobility profiles for career stages in terms of differences by gender or scientific field. We then compare the duration of mobility instances and whether they include a job change. Finally, we highlight researchers' motivations for mobility at different career stages.

\subsubsection{International mobility, field of science and gender}

The MORE2 survey found that $31 \%$ of European researchers had undertaken at least one long duration (>3 months) episode of international mobility in the previous ten years. ${ }^{7}$ The career stage of $\mathrm{PhD}$ qualified researchers does not appear to influence the likelihood of international mobility in the different fields (Table 3). The single exception is that mobility is more likely to occur at career stage R2 than career stage R3 in the natural sciences.

\footnotetext{
${ }^{7}$ Researchers in natural sciences $(38 \%)$ were the most likely to be internationally mobile, followed by engineering and technology (31\%), humanities (30\%), social sciences (30\%), medical sciences $(27 \%)$ and agricultural sciences (24\%) (Idea Consult 2013). Note: figures include all mobile researchers (R1-R4).
} 
Table 3: International mobility instances by field of research and gender, by career stage

\begin{tabular}{|c|c|c|c|c|c|c|c|c|c|c|c|}
\hline \multirow[t]{2}{*}{ Career Stage } & \multicolumn{2}{|c|}{$\mathbf{R} 2$} & \multicolumn{2}{|c|}{ R3 } & \multicolumn{2}{|c|}{ R4 } & \multicolumn{2}{|c|}{ Total } & \multirow[t]{2}{*}{$\begin{array}{l}\text { R2- } \\
\text { R3 }\end{array}$} & \multirow[t]{2}{*}{$\begin{array}{c}\text { R3- } \\
\text { R4 }\end{array}$} & \multirow[t]{2}{*}{$\begin{array}{l}\text { R2- } \\
\text { R4 }\end{array}$} \\
\hline & \multicolumn{8}{|c|}{ International mobility instances by field of research } & & & \\
\hline Agricultural Sciences & 47 & $2.7 \%$ & 35 & $3.9 \%$ & 37 & $7.3 \%$ & 119 & $3.8 \%$ & & & \\
\hline Engineering \& Tech. & 281 & $16.0 \%$ & 124 & $13.9 \%$ & 81 & $16.0 \%$ & 486 & $15.4 \%$ & & & \\
\hline Humanities & 218 & $12.4 \%$ & 152 & $17.0 \%$ & 74 & $14.7 \%$ & 444 & $14.1 \%$ & & & \\
\hline Medical Sciences & 286 & $16.3 \%$ & 159 & $17.8 \%$ & 70 & $13.9 \%$ & 515 & $16.3 \%$ & & & \\
\hline Natural Sciences & 517 & $29.4 \%$ & 193 & $21.6 \%$ & 117 & $23.2 \%$ & 827 & $26.2 \%$ & ++ & & \\
\hline \multirow[t]{2}{*}{ Social Sciences } & 407 & $23.2 \%$ & 229 & $25.7 \%$ & 126 & $25.0 \%$ & 762 & $24.2 \%$ & & & \\
\hline & \multicolumn{8}{|c|}{ International mobility instances by gender } & & & \\
\hline Women $(n=657)$ & 648 & $36.9 \%$ & 280 & $31.4 \%$ & 76 & $15.0 \%$ & 1,004 & $31.8 \%$ & & +++ & +++ \\
\hline Men $(n=1,338)$ & 1,108 & $63.1 \%$ & 612 & $68.6 \%$ & 429 & $85.0 \%$ & 2,149 & $68.2 \%$ & -- & --- & -- \\
\hline $\begin{array}{l}\text { Total mobility } \\
\text { instances }\end{array}$ & 1,756 & $100.0 \%$ & 892 & $100.0 \%$ & 505 & $100.0 \%$ & 3,153 & $100.0 \%$ & & & \\
\hline
\end{tabular}

* Significant positive differences $(\mathrm{R} 2>\mathrm{R} 3, \mathrm{R} 3>\mathrm{R} 4$ or R2>R4) are shown for different significance levels ("+++" at 0.01, "++" at 0.05 and "+" at 0.10). Accordingly, significant negative differences (R2<R3, $\mathrm{R} 3<\mathrm{R} 4$ or R2<R4) are shown for different levels ("---" at 0.01 , "--" at 0.05 and "-" at 0.10 ). We use the same presentation for all tables in Section 6.1.

Overall, women researchers $(n=657,32.9 \%$ of our mobile researcher target group) undertook $31.8 \%$ of all international mobility instances reported $(n=1,004)$. At the $R 2$ career stage, this figure was $36.9 \%(\mathrm{n}=648)$, compared to $31.4 \%$ at the R3 stage and just $15 \%$ at the $\mathrm{R} 4$ stage. The proportion of mobility instances undertaken by women is significantly higher at R2 and R3 career stages compared to the R4 stage (Table 3). In complete contrast, for men international mobility is significantly less likely to occur the earlier the career stage. From these results, the career stage timing of international mobility appears to be strongly gendered. The number of mobility instances performed by women at the R4 career stage is low in absolute terms, likely reflecting the systemic under-representation of women at the highest levels of academic careers in Europe (European Commission 2016).

\subsubsection{Duration of international mobility and job change}

The duration of international mobility instances of three months or longer were divided into five different categories (Table 4). International visits of three to six months are the most common form of mobility instance, representing $43 \%$ of all reported mobility instances $(n=1370)$, including $36 \%$ of all mobility at stage $R 2(n=648), 48 \%$ at stage $R 3$ 
( $\mathrm{n}=434)$ and $56 \%$ at stage $\mathrm{R} 4(\mathrm{n}=288)$. Mobility at $\mathrm{R} 2$ stage is significantly less likely to be of 3-6 months duration compared to mobility at the R3 and R4 stages.

Table 4: International mobility instances, duration and change in employer, by career stage

\begin{tabular}{|c|c|c|c|c|c|c|c|c|c|c|c|}
\hline $\begin{array}{l}\text { Career } \\
\text { Stage }\end{array}$ & \multicolumn{2}{|c|}{$\mathbf{R 2}$} & \multicolumn{2}{|c|}{$\mathbf{R 3}$} & \multicolumn{2}{|c|}{ R4 } & \multicolumn{2}{|c|}{ Total } & $\begin{array}{l}\text { R2- } \\
\text { R3 }\end{array}$ & $\begin{array}{l}\text { R3- } \\
\text { R4 }\end{array}$ & $\begin{array}{l}\text { R2- } \\
\text { R4 }\end{array}$ \\
\hline \multicolumn{9}{|c|}{ Duration (months) } & & & \\
\hline $3-6$ & 648 & $36.9 \%$ & 434 & $48.7 \%$ & 288 & $57.0 \%$ & 1,370 & $43.5 \%$ & \multirow{5}{*}{---} & \multirow[t]{5}{*}{--} & \multirow[t]{5}{*}{--} \\
\hline $6-12$ & 303 & $17.3 \%$ & 149 & $16.7 \%$ & 76 & $15.0 \%$ & 528 & $16.7 \%$ & & & \\
\hline $12-24$ & 287 & $16.3 \%$ & 100 & $11.2 \%$ & 38 & $7.5 \%$ & 425 & $13.5 \%$ & & & \\
\hline $24-36$ & 200 & $11.4 \%$ & 51 & $5.7 \%$ & 21 & $4.2 \%$ & 272 & $8.6 \%$ & & & \\
\hline $36+$ & 318 & $18.1 \%$ & 158 & $17.7 \%$ & 82 & $16.2 \%$ & 558 & $17.7 \%$ & & & \\
\hline \multicolumn{9}{|c|}{ Change in employer } & & & \\
\hline No & 874 & $49.8 \%$ & 556 & $62.3 \%$ & 358 & $70.9 \%$ & 1,788 & $56.7 \%$ & --- & --- & --- \\
\hline Yes & 882 & $50.2 \%$ & 336 & $37.7 \%$ & 147 & $29.1 \%$ & 1,365 & $43.3 \%$ & +++ & + & +++ \\
\hline Total & 1,756 & $100.0 \%$ & 892 & $100.0 \%$ & 505 & $100.0 \%$ & 3,153 & $100.0 \%$ & & & \\
\hline
\end{tabular}

Overall, a job change is associated with $43.3 \%(n=1,365)$ of international mobility instances. However, this figure is $50 \%$ at the $\mathrm{R} 2$ stage of the career $(\mathrm{n}=882)$, compared with $37.7 \%$ and $29.1 \%$ at career stages R3 and R4 respectively. International mobility that involves changing jobs is significantly more likely to occur at stage R2 of the career than at stage R3 or stage R4. Similarly, international mobility that involves changing jobs is significantly more likely to occur at stage R3 than at stage R4.

\subsubsection{Motivations for international mobility, by career stage}

For their most recent instance of international mobility, respondents were asked to rate the relative importance of a set of potential motivations for the move (Table 5). We classified responses into three groups $(\mathrm{R} 2, \mathrm{R} 3, \mathrm{R} 4)$ depending on the career stage at the start of the mobility instance. This enables us to compare motivations for mobility at different career stages. The results of these comparisons are summarised in the mobility profiles shown in Table 6. 
Table 5. Important factors determining decisions to move (most recent instance of mobility)*

\begin{tabular}{|l|rrr|rrr|}
\hline \multirow{2}{*}{ Motivations } & \multicolumn{5}{|c|}{ Career stage } & \multicolumn{3}{c|}{ Differences } \\
& \multicolumn{1}{|c|}{$R 2$} & $R 3$ & $R 4$ & $R 3$ & $R 3-$ & $R 2-$ \\
& & $R 4$ & $R 4$ \\
\hline Availability of research funding & $68.9 \%$ & $66.9 \%$ & $65.1 \%$ & & & \\
Availability of suitable positions & $67.2 \%$ & $63.3 \%$ & $59.5 \%$ & & & ++ \\
Positive impact on future career progression & $83.5 \%$ & $79.7 \%$ & $70.5 \%$ & + & +++ & +++ \\
Facilities and equipment for research & $68.9 \%$ & $71.4 \%$ & $69.1 \%$ & & & \\
Working with leading experts & $70.2 \%$ & $75.3 \%$ & $75.1 \%$ & -- & & - \\
Quality of training and education & $59.0 \%$ & $59.9 \%$ & $59.8 \%$ & & & \\
Culture and language & $59.6 \%$ & $60.2 \%$ & $56.9 \%$ & & & \\
Personal / family reasons & $49.8 \%$ & $53.2 \%$ & $50.4 \%$ & & & \\
Research autonomy & $45.5 \%$ & $47.7 \%$ & $53.6 \%$ & & & -- \\
Remuneration (salary or other) & $42.7 \%$ & $34.5 \%$ & $40.2 \%$ & +++ & & \\
Social security and pension system & $27.5 \%$ & $22.4 \%$ & $27.8 \%$ & ++ & - & \\
Job security & $32.5 \%$ & $28.4 \%$ & $31.1 \%$ & + & & \\
Working conditions & $59.0 \%$ & $58.3 \%$ & $64.5 \%$ & & - & - \\
\hline Sample size & 1,167 & 505 & 275 & & & \\
\hline
\end{tabular}

* Researchers were asked to rate whether each factor was important or not important as a motivation for their last registered instance of mobility. Table 5 shows the percentage of respondents who rated a motivation as 'important', distributed according to their career stage at the start of the corresponding mobility instance. Of our total sample of 1,995 most recent mobility instances, 48 did not include complete information for these questions, leaving a total of 1,947 mobility instances for these career stage comparisons. 


\subsubsection{Summary}

Our initial expectations regarding the descriptive part of our empirical analysis were that profiles of international mobility associated with recognised, established and leading researcher career stages $(\mathrm{R} 2, \mathrm{R} 3, \mathrm{R} 4)$ would be different. These expectations are largely confirmed (Table 6). ${ }^{8}$

\section{Table 6: International mobility profiles by research career stage}

\begin{tabular}{|c|c|c|}
\hline Recognised researcher $(\mathbf{R 2})$ & Established researcher (R3) & Leading researcher (R4) \\
\hline $\begin{array}{l}\text { Short duration international } \\
\text { mobility ( } 3-6 \text { months) least } \\
\text { likely at this stage }\end{array}$ & $\begin{array}{l}\text { Short duration international } \\
\text { mobility ( } 3-6 \text { months) less likely } \\
\text { than for leading researchers }\end{array}$ & $\begin{array}{l}\text { Relatively higher frequency of } \\
\text { international mobility instances } \\
\text { per researcher }\end{array}$ \\
\hline $\begin{array}{l}\text { Medium duration international } \\
\text { mobility (1-2 years) more likely } \\
\text { at this stage than leading } \\
\text { researcher stage }\end{array}$ & $\begin{array}{l}\text { International mobility more } \\
\text { likely to be associated with job } \\
\text { changes than for leading } \\
\text { researchers }\end{array}$ & $\begin{array}{l}\text { International mobility most } \\
\text { likely to not be associated with } \\
\text { job changes at this stage }\end{array}$ \\
\hline $\begin{array}{l}\text { International mobility most } \\
\text { likely to be associated with job } \\
\text { changes at this stage }\end{array}$ & $\begin{array}{l}\text { Women are more likely to be } \\
\text { mobile at this stage than at } \\
\text { leading researcher stage }\end{array}$ & $\begin{array}{l}\text { International mobility most } \\
\text { strongly motivated by access to } \\
\text { better working conditions at this } \\
\text { stage }\end{array}$ \\
\hline $\begin{array}{l}\text { Women are more likely to be } \\
\text { mobile at this stage than at the } \\
\text { leading researcher stage } \\
\text { Men are least likely to be } \\
\text { internationally mobile at this } \\
\text { stage }\end{array}$ & $\begin{array}{l}\text { Men are less likely to be } \\
\text { internationally mobile at this } \\
\text { stage than at the leading } \\
\text { researcher stage } \\
\text { Mobility strongly motivated by } \\
\text { perceived boost to career } \\
\text { progress }\end{array}$ & $\begin{array}{l}\text { International mobility more } \\
\text { strongly motivated by research } \\
\text { autonomy and possibility to } \\
\text { work with leading experts } \\
\text { compared to recognised } \\
\text { researchers }\end{array}$ \\
\hline $\begin{array}{l}\text { Natural science researchers more } \\
\text { likely to be mobile at this stage } \\
\text { than at the established researcher } \\
\text { stage }\end{array}$ & & \\
\hline $\begin{array}{l}\text { International mobility strongly } \\
\text { motivated by perceived boost to } \\
\text { career progress }\end{array}$ & & \\
\hline $\begin{array}{l}\text { International mobility motivated } \\
\text { by availability of suitable } \\
\text { positions, salary, social security } \\
\text { and job security in comparison } \\
\text { to the established career phase }\end{array}$ & & \\
\hline $\begin{array}{l}\text { Less motivated by working with } \\
\text { leading experts in comparison to } \\
\text { later career stages }\end{array}$ & & \\
\hline
\end{tabular}

\footnotetext{
${ }^{8}$ Results for differences between career stages shown in this section were also further analysed by preferred geographical destinations for international mobility, but no significant results were found.
} 


\subsection{Career advancement and international mobility}

The purpose of this section is to address the potential connection between career advancement and international mobility, notably since this relationship seems to be strongly perceived by researchers themselves (Table 5). Table 7 shows the distribution of mobility instances both in percentage and total numbers, according to the career stages at which they start (Rs) and they end (Re).

Table 7: International mobility episodes, by career stage at start and end

\begin{tabular}{|lrrrrrrrrrr|}
\hline Transitions & R2-R2 & R2-R3 & R2-R4 & R3-R2 & R3-R3 & R3-R4 & R4-R2 & R4-R3 & R4-R4 & Total \\
\hline Percentage & $44.02 \%$ & $10.66 \%$ & $1.01 \%$ & $0.19 \%$ & $24.77 \%$ & $3.33 \%$ & $0.10 \%$ & $0.25 \%$ & $15.67 \%$ & $100.00 \%$ \\
N & 1,388 & 336 & 32 & 6 & 781 & 105 & 3 & 8 & 494 & 3,153 \\
\hline
\end{tabular}

Career stage advancement happens in at total of $15 \%$ of international mobility instances, R2-R3 (10.6\%), R3-R4 (3.3\%) and R2-R4 (1\%). The vast majority of international mobility instances (84\%) starts and finishes within the same career stage. There are also a small number of career regressions occurring in international mobility instances $(0.5 \%)$. Figure 1 combines these data on mobility and career advancement with data on mobility and change of employer.

Figure 1: International mobility associated with change of employer and career stage advancement

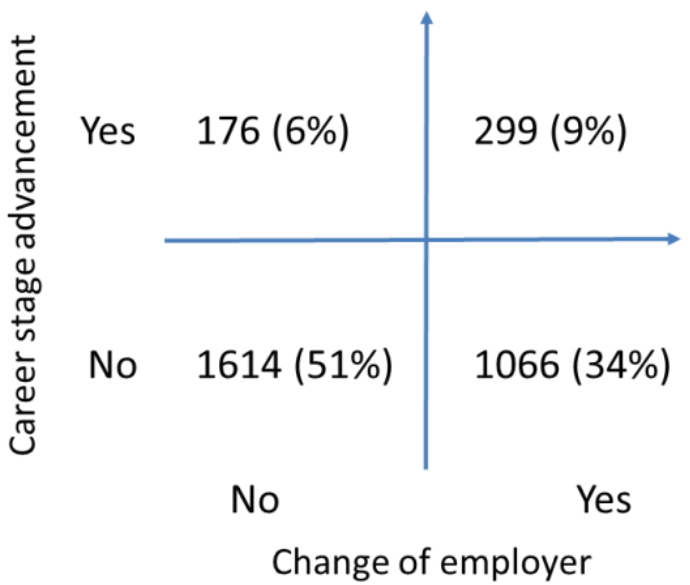


The figure shows that half of all international mobility instances involve neither a change in employer, nor a career stage advance. A further $33.8 \%$ of international mobility instances involve a job change, but not career stage advancement. A smaller proportion $(15.0 \%)$ of international mobility instances is concurrent with career stage advancement. These figures also suggest that career advancement and change of employer are often concurrent: for mobility instances involving career advancement (475 cases) the proportion of these involving a change of employer is $63 \%$, compared to $43 \%$ for all mobility instances.

In what follows, we address the factors that might be influencing two types of career advancement that are associated with different features of international mobility instances. We examine this by means of logistic regressions as described in section 5 . Our dependent variables are dichotomous, taking value 1 if there is a change in career stage when comparing the beginning and end of a mobility instance (and zero otherwise). To examine the first type of career stage advancement (R2 to R3 and R2 to R4) we analyse the sub-sample of mobility instances where researchers report a career stage corresponding to $\mathrm{R} 2$ at the start of the mobility. This amounts to 1,756 observations. Similarly, to examine the second type of career advancement (R3 to R4) we examine the sub-sample of mobility instances for which researchers reported a career stage R3 at the start of the mobility (892 observations).

It is important to note that we have controlled for the fact that the same researchers have been involved in more than one instance of mobility within our period of analysis. In fact, the mobile researchers responsible for our sample of mobility instances report 1.58 instances of mobility on average (ranging from 1 minimum, to 8 as a maximum). For this reason we have conducted our logistic regressions controlling for the correlation associated to mobility instances that correspond to the same individual researcher (i.e., clustering by individual identifier), to take account of the fact that individual researchers' characteristics are common to different observations of instances of mobility in our sample. The other note is that, due to missing data on $\mathrm{PhD}$ age and information about country of $\mathrm{PhD}$ award, we have full data for a smaller sample than the original dataset (1472 observations rather than 1756, corresponding to instances of international mobility starting at career stage R2; and 722 observations rather than 892 , corresponding to instances of international mobility starting at career stage R3). Tables 
A1 and A2 in the Appendix show the proportion of mobility instances associated with the two types of career advancement: $20 \%$ and $12 \%$, respectively.

Table 8 shows the results of the logistic regressions. The first column (M1) corresponds to the first type of career advancement (R2 to R3/R4), while the second column (M2) corresponds to the second type of career advancement (R3 to R4). The results from Table 8 show that prior mobility and return mobility have a statistically significant and positive association with career stage advancement in the context of mobility episodes. However, their influence is different depending on the type of career advance we examine. We find that prior mobility is particularly strongly associated to career advancement of type 1 ( $\mathrm{R} 2$ to $\mathrm{R} 3 / \mathrm{R} 4)$, while return mobility is associated to career advancement of type 2 (R3 to R4). In both cases the duration of the mobility instances is an important factor associated with the probability of career advancement. However, $\mathrm{PhD}$ age seems to be only associated with career advancement type 1 and change of employer has no statistically significant relationship with either of the two career transitions examined. 
Table 8: Career stage advancement associated with international mobility, logistic regression results

\begin{tabular}{|c|c|c|c|c|}
\hline & \multicolumn{2}{|c|}{$\begin{array}{c}\text { Career Advancement 1: } \\
\text { R2 to R3/R4 } \\
\end{array}$} & \multicolumn{2}{|c|}{$\begin{array}{c}\text { Career Advancement 2: } \\
\text { R3 to R4 } \\
\end{array}$} \\
\hline & M1a & M1b & $\mathrm{M} 2 \mathrm{a}$ & $\mathrm{M} 2 \mathrm{~b}$ \\
\hline Return Mobility & $\begin{array}{c}0.169 \\
(0.220)\end{array}$ & $\begin{array}{c}0.028 \\
(0.251)\end{array}$ & $\begin{array}{c}0.695^{* *} \\
(0.306)\end{array}$ & $\begin{array}{c}1.509 * * * \\
(0.493)\end{array}$ \\
\hline $\mathrm{PhD}$ age & $\begin{array}{c}0.030 * * \\
(0.012)\end{array}$ & $\begin{array}{c}0.027 * * \\
(0.012)\end{array}$ & $\begin{array}{c}0.024 \\
(0.018)\end{array}$ & $\begin{array}{c}0.037 * * \\
(0.019)\end{array}$ \\
\hline Return Mobility $* \mathrm{PhD}$ age & --- & $\begin{array}{c}0.055 \\
(0.044)\end{array}$ & --- & $\begin{array}{c}-0.111 * * \\
(0.054)\end{array}$ \\
\hline Prior Mobility & $\begin{array}{c}0.233 * * \\
(0.113)\end{array}$ & $\begin{array}{l}0.230 * * \\
(0.113)\end{array}$ & $\begin{array}{l}0.070 \\
(0.119)\end{array}$ & $\begin{array}{l}0.083 \\
(0.121)\end{array}$ \\
\hline PhD Abroad & $\begin{array}{l}-0.024 \\
(0.172)\end{array}$ & $\begin{array}{l}-0.011 \\
(0.171)\end{array}$ & $\begin{array}{c}0.379 \\
(0.304)\end{array}$ & $\begin{array}{l}0.372 \\
(0.310)\end{array}$ \\
\hline Change of employer & $\begin{array}{l}-0.075 \\
(0.174)\end{array}$ & $\begin{array}{l}-0.071 \\
(0.174)\end{array}$ & $\begin{array}{c}0.166 \\
(0.313)\end{array}$ & $\begin{array}{c}0.133 \\
(0.319)\end{array}$ \\
\hline 6-12 months duration & $\begin{array}{l}0.471 * \\
(0.251)\end{array}$ & $\begin{array}{l}0.472 * \\
(0.251)\end{array}$ & $\begin{array}{c}0.134 \\
(0.470)\end{array}$ & $\begin{array}{c}0.174 \\
(0.468)\end{array}$ \\
\hline $12-24$ months duration & $\begin{array}{c}0.998 * * * \\
(0.243)\end{array}$ & $\begin{array}{c}0.995 * * * \\
(0.243)\end{array}$ & $\begin{array}{c}0.879 * * \\
(0.431)\end{array}$ & $\begin{array}{c}0.959 * * \\
(0.430)\end{array}$ \\
\hline 24-36 months duration & $\begin{array}{l}1.347 * * * \\
(0.260)\end{array}$ & $\begin{array}{l}1.344 * * * \\
(0.260)\end{array}$ & $\begin{array}{l}1.615^{* * *} \\
(0.497)\end{array}$ & $\begin{array}{l}1.646 * * * \\
(0.503)\end{array}$ \\
\hline$>36$ months duration & $\begin{array}{c}2.188 * * * \\
(0.236)\end{array}$ & $\begin{array}{c}2.203 * * * \\
(0.236)\end{array}$ & $\begin{array}{c}1.420 * * * \\
(0.393)\end{array}$ & $\begin{array}{c}1.462 * * * \\
(0.399)\end{array}$ \\
\hline Male & $\begin{array}{l}-0.022 \\
(0.154)\end{array}$ & $\begin{array}{l}-0.027 \\
(0.154)\end{array}$ & $\begin{array}{c}0.023 \\
(0.305)\end{array}$ & $\begin{array}{c}0.002 \\
(0.303)\end{array}$ \\
\hline Constant & $\begin{array}{l}-2.975 * * * \\
(0.574)\end{array}$ & $\begin{array}{l}-2.951 * * * \\
(0.577)\end{array}$ & $\begin{array}{c}-3.648 * * * \\
(0.676)\end{array}$ & $\begin{array}{c}-3.685 * * * \\
(0.697)\end{array}$ \\
\hline Country of PhD (dummies) & Included & Included & Included & Included \\
\hline Country destination (dummies) & Included & Included & Included & Included \\
\hline Discipline dummies & Included & Included & Included & Included \\
\hline $\mathrm{N}$ & 1472 & 1472 & 722 & 722 \\
\hline Wald chi2 & $156.27 * * *$ & $157.02 * * *$ & $68.00 * * *$ & $70.85 * * *$ \\
\hline McKelvey \& Zavoina's R ${ }^{2}$ & 0.19 & 0.19 & 0.22 & 0.23 \\
\hline
\end{tabular}

$* p<0.10 ; * *<<0.05 ; * * * p<0.01$. Standard errors are robust and clustered at the individual researcher level. The mobility duration ' $3-6$ ' months is used as reference category. Country of PhD includes dichotomous variables to indicate whether the country of $\mathrm{PhD}$ award of the mobile researcher corresponds to Central Europe, North America, or UK (being all other countries the reference category). Country destination includes dichotomous variables to indicate whether the country of destination of a mobility episode corresponds to Central Europe, North America or UK (being all other countries the reference category). Finally, discipline dummies include dummies for the scientific field of the scientific researcher: Engineering and Technology; Humanities; Medical Sciences; Natural Sciences; and Social Sciences (Agricultural Sciences being the reference category). ${ }^{9}$

\footnotetext{
${ }^{9}$ We have not included the estimated results for these variables to facilitate the reading of this table. Full set of results are available upon request.
} 
As the likelihood of return mobility during a particular career stage may also be influenced by the duration of the research career, we included the interplay between return mobility and $\mathrm{PhD}$ age in our model. In the case of career advancement of type 2, we observe that there is a negative interplay between return mobility and $\mathrm{PhD}$ age. This result suggests that for established researchers (R3 stage) a longer time span since their $\mathrm{PhD}$ award reduces the likelihood that return mobility would be associated to type 2 career advancement. This interplay is illustrated in Figure 2, which captures the results from the logistic regression M2b (Table 8). In contrast, we do not observe any significant interplay between return mobility and $\mathrm{PhD}$ age in the case of career advancement of type 1 (R2 to R3/R4).

Figure 2: Interplay between "return mobility" and "PhD age", career stage advancement 2 (R3 to R4)

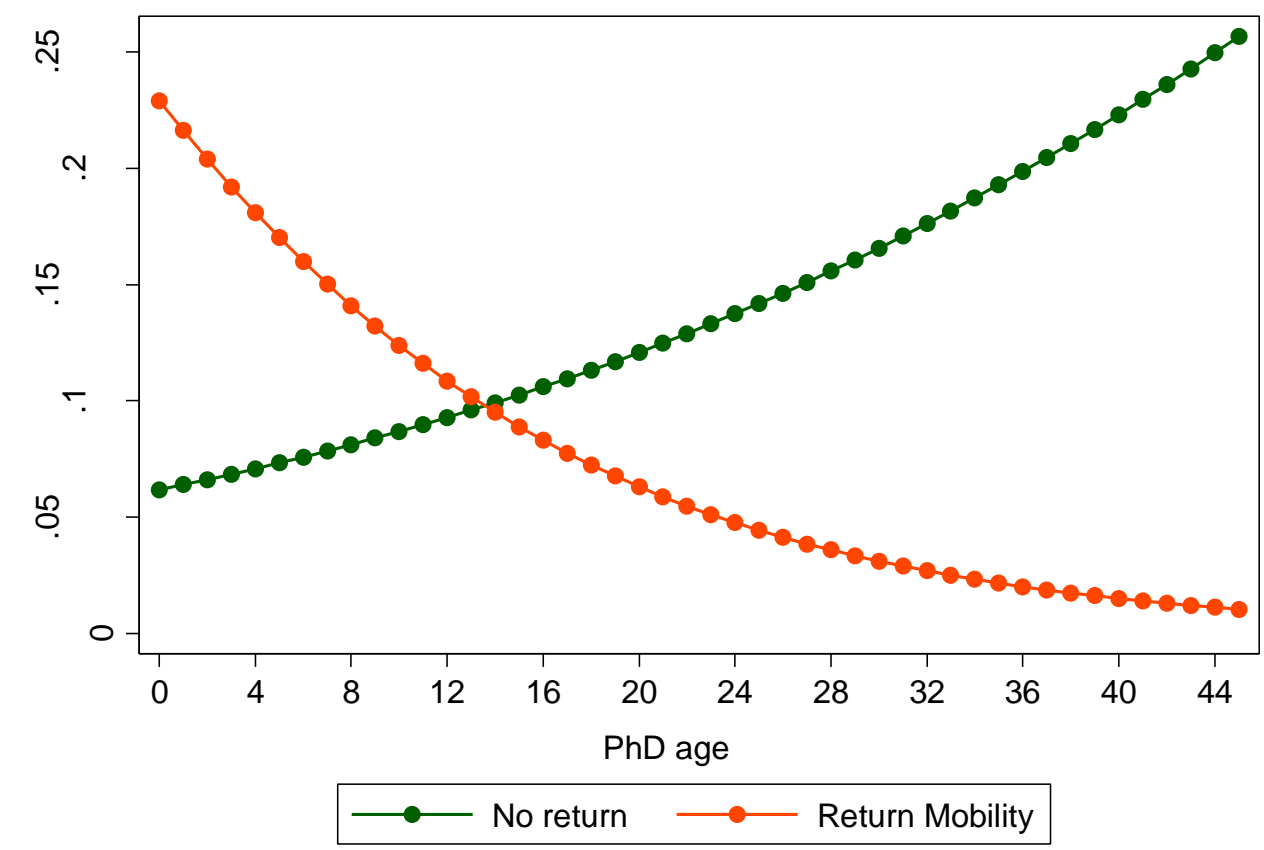

\section{Discussion and conclusions}

In this paper we have re-used the MORE2 dataset to examine linkages between academic researchers' career stage and international mobility instances, among mobile 
researchers. Re-using a secondary dataset meant going through a series of methodological steps to refine research questions for which the available data were a good fit. Our research questions and analyses were developed also in light of the 'three careers' model of academic research careers (Gläser and Laudel 2015). This model involves three intertwined career processes, cognitive, community and organisational, which together can explain career trajectories and outcomes. We used information from MORE2 on researchers' self-perceptions of their progress through a series of four career stages defined by the acquisition of research competences in combination with information about changes of employer (organisational career). This allowed us to examine whether career stage advances were associated with international mobility, including where this involved a change in employer. We considered the career stage framework based on the acquisition of research competences to be somewhat of a hybrid of cognitive and community career processes as it includes elements both of individual skills and capabilities and of presumed recognition and standing within the scientific peer community. The major difference here is in the way the research career stage data has been collected as individual self-report data in responding to a survey questionnaire. Prior studies which have investigated research careers using the three careers model have used qualitative interviews, bibliometric analysis and network mapping techniques. To the best of the authors' knowledge this is the first time this model has been used in a quantitative study of international scientific mobility.

As previous research has intimated (Ackers and Gill 2008, Bauder 2015; Cañibano et al 2008; Laudel and Bielick 2019), the analysis of our first research question found that the duration of international mobility is determined by researchers' career stage in some respects. International mobility is also apparently driven most strongly by different motivations at each career stage. International mobility is also clearly gendered in its career timing, with women more likely to be internationally mobile at early and midcareer stages (R2 and R3) than in the advanced career stage (R4), whereas men are most likely to be mobile in the most advanced stage (R4).

Importantly, we found that mobility is more likely to be associated with a job change in the early career phase. This is consistent with the arguments of Laudel and Bielick (2019) regarding the functions of mobility for the development of ECRs' cognitive careers, particularly by establishing their autonomy through an independent research project. In disciplines where new learning post-PhD is essential, mobility is particularly 
important they argue. This may also be the case in situations where the national scientific community is relatively small in a discipline. This result also reflects general arguments regarding the necessity for many ECRs to be mobile to obtain entry level positions in their field. Our finding that mobility for job change occurs most frequently in the ECR phase might therefore have different explanations linked to different career processes. The international mobility of ECRs to take up a new job might well function to resolve tensions in the synchronisation of researchers' cognitive and organisational careers.

The analyses conducted for our second research question found that while career advance and different features of international mobility instances are positively associated, the importance of these factors varied by the career stage of mobile researchers. Advancing from the early career stage (R2) to mid-career (R3) or advanced (R4) stage was associated with the number of years elapsed since the $\mathrm{PhD}$ award at the time of the international mobility and also with the number of prior mobility episodes. Advancing from the mid-career stage (R3) to the advanced stage (R4) was associated with the international mobility being return mobility to the country of the $\mathrm{PhD}$ award, which answered our third research question. In relation to the this question, progression to the advanced stage associated with return mobility is more likely provided the return does not occur too many years after the researcher's $\mathrm{PhD}$ was awarded.

The duration of mobility instances was found to be a consistently influential factor across both career stage advancements examined. Interestingly mobility for a job change was not associated with career advancement for either type of the career stage advancement. This is a reminder of the importance of other forms of extended international mobility, such as research visits. It also reinforces the analytical importance of viewing research careers as involving multiple processes and not simply as sequences of organisational positions.

Our results suggest findings that are relevant both to scholarship on research careers and researcher mobility and to policies associated with geo-political initiatives such as the EHEA and the ERA. The relative importance of international mobility for ECRs to obtain a paid position, and the likely multiple career reasons underlying this finding, reinforces the objectives of the ERA to create a free and open labour market for researchers in Europe. 
Like previous studies that found mixed results (Lawson and Shibayama 2015, Marinelli et al. 2014), we find that under certain conditions international mobility has a beneficial effect on the careers of mobile researchers. In addition, we find that international mobility can lead to an eventual payoff to the 'home' research system. In particular, there appear to be benefits accruing to researchers who are prepared to make a move away from their home country to work and then seek to return. Established mid-career researchers who make a timely return home have improved chances of this move involving career advancement. This incentive to return home can help compensate for the earlier loss of a highly trained individual, along with the additional networking and learning benefits that are likely to be associated with returnees.

To conclude, recognising that international academic mobility is career stage dependent has important implications for HEI policies and institutional governance. HEIs that support their senior staff to use international visits to enhance their autonomous research programmes, in collaboration with leading experts, may well obtain both knowledge and loyalty benefits. HEIs that facilitate moves from other countries that enable early career researchers to establish independent research programmes are likely to reap benefits in terms of new knowledge in-flows, innovation and productivity outcomes. The key then is also to understand that some of these in-flows will later become outflows as, for combinations of professional and personal reasons, some researchers will seek to again contribute to their home countries' research effort and culture. Finally, institutional policies associated with immigration, access to labour markets and to health care, and recognition of foreign qualifications, for both researchers and for their immediate family members, need to be in place to support mechanisms that facilitate the mobility of highly qualified talents. But crucially such institutional policies need to be a common feature of countries motivated to participate in scientific research because 'open door' policies will only confer mutual benefits over time if the doors are double-hinged.

\section{Potential Conflict of Interest}

Carolina Cañibano wishes to declare that she was contracted as an expert by IDEA Consult to provide advice on the Spanish institutional framework of Higher Education and Research Careers. This activity in no way influences the analysis and findings contained in this paper. She did not contribute to the design or development of the 
MORE2 higher education survey used in this paper. The other authors have no potential conflict of interest to declare. 


\section{References}

Ackers, L. (2008) Internationalisation, mobility and metrics: A new form of indirect discrimination, Minerva, 46: 411-35

Ackers, L. (2013) Internet mobility, co-presence and purpose: contextualising internationalisation in research careers, Sociology and Techno-science, 3: 117-141

Ackers, L. and B. Gill (2008) Moving people and knowledge. Scientific mobility in an enlarging European Union. Edward Elgar, Cheltenham, Northhampton.

Andújar, I.; Cañibano, C. \& Fernández-Zubieta, A. (2015) International stays abroad, collaborations and the return of Spanish researchers. Science, Technology and Society, Vol.20(3): 322-348

Asknes, D.W.; K. Rostard, F.N. Piro and G. Sivertsen (2013) Are mobile researchers more productive and cited than non-mobile researchers? A large-scale study of Norwegian scientists. Research Evaluation, 22: 215-223.

Barjak, F.; \& S. Robinson (2008) International collaboration, mobility and team diversity in the life sciences: impact on research performance. Social Geography, 3:2336.

Bauder, H. (2015) The international mobility of academics: A labour market perspective, International Migration, 53(1), pp. 83-96.

Børing, P.; K. Flanagan, D. Gagliardi, A. Kaloudis and A. Karakasidou (2015) International Mobility: findings from a survey of researchers in the EU. Science and Public Policy, 42(-): 811-826

Cañibano C., Otamendi, J. \& Andújar, I. (2008) Measuring and assessing researcher mobility from CV analysis: the case of the Ramon y Cajal programme in Spain. Research Evaluation, 17(1): 17- 31.

Cañibano, C. \& Woolley, R. (2015) Toward a socio-economics of the brain-drain and distributed human capital. International Migration, Vol. 53 (1): 115-130.

Cañibano, C.; Vértesy, D. \& Vezzulli, A. (2017) An inquiry into the return mobility of researchers in Europe. JRC Technical Report; European Commission

Doolan, D. and Froelicher, E. (2009) Using an existing data set to answer new research questions: A methodological review. Research and Theory for Nursing Practice: An International Journal, Vol. 23, No. 3: 203-17.

European Commission (2000) Towards a European Research Area. COM (2000)6. Retrieved: https://era.gv.at/object/document/139

European Commission. (2011) Towards a European framework for research careers. Directorate General for Research \&. Innovation, Brussels, July 21st. Retrieved: 
https://cdn5.euraxess.org/sites/default/files/policy_library/towards_a_european_framew ork_for_research_careers_final.pdf

European Commission (2016) She Figures 2015. Directorate General for Research and Innovation, Brussels.

European Ministers in Charge of Higher Education (1999) The European Higher Education Area: The Bologna Declaration of 19 June, 1999. Joint Declaration of the European Ministers of Education.

Fernández-Zubieta, A., Geuna, A., \& Lawson, C. (2015). What do we know of the mobility of research scientists and impact on scientific production. In A. Guena (Ed.), Global mobility of research scientists. The economics of who goes where and why. Amsterdam: Elsevier. Ch. 1: 1-33

Fontes, M. (2007). Scientific mobility policies: How Portuguese scientists envisage the return home. Science and Public Policy, 34(4), 284-298.

Franzoni, C.; G. Scellato and P. Stephan (2015) "International Mobility of Research Scientists: Lessons from GlobSci” in Geuna, A. (Ed) Global Mobility of Research Scientists. The economics of who goes where and why. Amsterdam: Elsevier. Chap. 2: $35-65$

Gibson, J. \& D. McKenzie (2014) Scientific mobility and knowledge networks in high emigration countries: evidence from the Pacific. Research Policy, 43: 1486-1495

Gläser, J., \& G. Laudel (2015) The three careers of an academic. Zentrum Technic und Gesellshaft, TU Berlin, Discussion Paper 35/2015

Halevi, G.; H.F. Moed and J. Bar-Ilan (2016) Researchers' mobility, productivity and impact: case of top producing authors in seven disciplines, Publishing Research Quarterly 32: 22-37.

Hyman, H. H. (1972) Secondary analysis of sample surveys: principles, procedures, and potentialities. New York: New York: Wiley, 1972.

IDEA Consult (2010) “Final Report MORE”. Brussels, June 2010. Retrieved: https://cdn3.euraxess.org/sites/default/files/policy_library/more_final_report_final_versi on.pdf

IDEA Consult (2013) “Final Report MORE2”. Brussels, August 2013. Retrieved: https://cdn4.euraxess.org/sites/default/files/policy_library/final_report_0.pdf

IDEA Consult (2017) "MORE3 Study". December 2017. Retrieved: https://cdn1.euraxess.org/sites/default/files/policy library/final report 2.pdf

Laudel, G. (2005). Migration currents among the Scientific Elite. Minerva, 43, 377395. 
Laudel, G. and Bielick, J. (2019) How do field-specific research practices affect mobility decisions of early career researchers? Research Policy 48(9) 103800 https://doi.org/10.1016/j.respol.2019.05.009

Laudel, G,; J. Bielick \& J. Gläser (2018). Ultimately the question always is: "What do I have to do to do it right?" Scripts as explanatory factors of career decisions. Human Relations, (in press).

Lawson, C., \& Shibayama, S. (2015). International research visits and careers: An analysis of bioscience academics in Japan. Science and Public Policy, 42(5): 690-710.

Lu, X. and W. Zhang (2015) The reversed brain drain: a mixed-method study of the reversed migration of Chinese overseas scientists. Science Technology and Society, 20(3): 279-299.

Mahroum, S. (2000). Scientific mobility: An agent of scientific expansion and institutional empowerment. Science Communication, 21(4): 367-378

Marceau, J., \& H. Preston (1997). Nurturing national talent: The Australian Research Council's fellowship scheme. Prometheus, 15(1), 41-54

Marinelli, E.; Fernandez-Zubieta Ana and Peréz, S. E. (2014) International Mobility and Career Consolidation of European Researchers. In Gérard, M. \& S. Uebelmesser (Eds.) The Mobility of Students and the Highly Skilled. CESifo CESifo Book Series. The MIT Press, pp.83-104.

Melin, G. (2004) Postdoc abroad: inherited scientific contacts or establishment of new networks? Research Evaluation, 13(2): 95-102

Moed, H. F., Aisati, M., \& Plume, A. (2013). Studying scientific migration in Scopus. Scientometrics, 94(3): 929-942.

Musselin, C. (2004) Towards a European academic labour market? Some lessons drawn from empirical studies on academic mobility. Higher Education, 48:55-78

Netz, N.; \& S. Jakstat (2017) Explaining scientists' plans for international mobility from a life course perspective. Research in Higher Education, 58(5): 497-519.

OECD (2015) Frascati Manual 2015. OECD Publishing, Paris. https://doi.org/10.1787/9789264239012-en

Paradeise, C. \& J.C. Thoenig (2015) In Search of Academic Quality, Palgrave Macmillan, London and New York.

Reale, E.; L. Morettini \& A. Zinilli (2018) Moving, remaining and returning: international mobility of doctorate holders in the social sciences and humanities, Higher Education 78(1): 17-32. 
Stephan, P. (2015). How economics shapes science. Cambridge MA. Harvard University Press.

Stewart, D. and Kamins, M. (1993) Applied Social Research Methods: Secondary research. Thousand Oaks, CA: SAGE Publications. doi: 10.4135/9781412985802

Thorn, K. and L.B. Holm-Nielsen (2006) International mobility of researchers and scientists: policy options for turning a drain into a gain. Research paper No. 2006/83. UNU-WIDER.

Veugelers, R., \& L. Van Bouwel (2015). The effects of international mobility on European researchers: Comparing intra-EU and US mobility. Research in Higher Education, 56, 360-377.

Wächter, B. (2008) 'Mobility and internationalisation in the European Higher Education Area' in Kelo, M. (Ed) Beyond 2010, Priorities and challenges for higher education in the next decade. ACA Papers on International Cooperation in Education: 13-42.

Woolley, R., T. Turpin, J. Marceau \& S Hill (2008) Mobility Matters: Research Training and Network Building in Science. Comparative Technology Transfer and Society 6(3):159-184.

Zippel, K. (2017) Women in Global Science. Advancing Academic Careers through International Collaboration, Stanford University Press, Stanford, California. 
Appendix A: Descriptive statistics

Table A1. Descriptive statistics: sub-sample of mobility starting at career stage $\mathbf{R} 2$ (1472 obs.)

\begin{tabular}{|c|c|c|c|c|}
\hline & Mean & Standard Dev. & Minimum & Maximum \\
\hline Career Advancement 1 & 0.226 & 0.419 & 0.000 & 1.000 \\
\hline Return Mobility & 0.101 & 0.301 & 0.000 & 1.000 \\
\hline $\mathrm{PhD}$ age & 3.825 & 6.179 & 0.000 & 42.000 \\
\hline Prior Mobility & 0.302 & 0.584 & 0.000 & 4.000 \\
\hline $\mathrm{PhD}$ abroad & 0.281 & 0.449 & 0.000 & 1.000 \\
\hline 3-6 months duration & 0.361 & 0.481 & 0.000 & 1.000 \\
\hline 6-12 months duration & 0.159 & 0.366 & 0.000 & 1.000 \\
\hline 12-24 months duration & 0.166 & 0.372 & 0.000 & 1.000 \\
\hline 24-36 months duration & 0.122 & 0.327 & 0.000 & 1.000 \\
\hline$>36$ months duration & 0.192 & 0.394 & 0.000 & 1.000 \\
\hline Male & 0.635 & 0.482 & 0.000 & 1.000 \\
\hline Change of employer & 0.514 & 0.499 & 0.000 & 1.000 \\
\hline Centre_Europe_PhD & 0.332 & 0.471 & 0.000 & 1.000 \\
\hline North_America_PhD & 0.067 & 0.251 & 0.000 & 1.000 \\
\hline UK_PhD & 0.111 & 0.314 & 0.000 & 1.000 \\
\hline Centre_Europe_destination & 0.353 & 0.478 & 0.000 & 1.000 \\
\hline North_America_destination & 0.216 & 0.412 & 0.000 & 1.000 \\
\hline UK_destination & 0.150 & 0.357 & 0.000 & 1.000 \\
\hline Agricultural Sciences & 0.027 & 0.163 & 0.000 & 1.000 \\
\hline Engineering & 0.164 & 0.370 & 0.000 & 1.000 \\
\hline Humanities & 0.102 & 0.303 & 0.000 & 1.000 \\
\hline Medical Sciences & 0.169 & 0.376 & 0.000 & 1.000 \\
\hline Natural Sciences & 0.310 & 0.463 & 0.000 & 1.000 \\
\hline Social Sciences & 0.228 & 0.419 & 0.000 & 1.000 \\
\hline
\end{tabular}

Continued next page 
Table A2. Descriptive statistics: sub-sample of mobility starting at career stage R3 (722 obs.)

\begin{tabular}{|c|c|c|c|c|}
\hline & Mean & Standard Dev. & Minimum & Maximum \\
\hline Career Advancement 2 & 0.122 & 0.322 & 0.000 & 1.000 \\
\hline Return Mobility & 0.115 & 0.319 & 0.000 & 1.000 \\
\hline $\mathrm{PhD}$ age & 8.680 & 7.160 & 0.000 & 45.000 \\
\hline Prior Mobility & 0.702 & 0.978 & 0.000 & 5.000 \\
\hline PhD abroad & 0.276 & 0.447 & 0.000 & 1.000 \\
\hline 3-6 months duration & 0.471 & 0.499 & 0.000 & 1.000 \\
\hline 6-12 months duration & 0.173 & 0.379 & 0.000 & 1.000 \\
\hline 12-24 months duration & 0.112 & 0.316 & 0.000 & 1.000 \\
\hline 24-36 months duration & 0.059 & 0.237 & 0.000 & 1.000 \\
\hline$>36$ months duration & 0.184 & 0.388 & 0.000 & 1.000 \\
\hline Male & 0.679 & 0.467 & 0.000 & 1.000 \\
\hline Centre_Europe_PhD & 0.332 & 0.471 & 0.000 & 1.000 \\
\hline North_America_PhD & 0.058 & 0.252 & 0.000 & 1.000 \\
\hline UK_PhD & 0.111 & 0.314 & 0.000 & 1.000 \\
\hline Centre_Europe_destination & 0.337 & 0.473 & 0.000 & 1.000 \\
\hline North_America_destination & 0.229 & 0.421 & 0.000 & 1.000 \\
\hline UK_destination & 0.126 & 0.332 & 0.000 & 1.000 \\
\hline Agricultural Sciences & 0.042 & 0.199 & 0.000 & 1.000 \\
\hline Engineering & 0.140 & 0.347 & 0.000 & 1.000 \\
\hline Humanities & 0.170 & 0.376 & 0.000 & 1.000 \\
\hline Medical Sciences & 0.173 & 0.379 & 0.000 & 1.000 \\
\hline Natural Sciences & 0.217 & 0.413 & 0.000 & 1.000 \\
\hline Social Sciences & 0.258 & 0.438 & 0.000 & 1.000 \\
\hline
\end{tabular}

